\title{
INFLUENCE OF THE CAFFEINE ON THE INTERACTION BETWEEN HALOPERIDOL AND HUMAN SERUM ALBUMIN: SPECTROSCOPIC AND MOLECULAR DOCKING APPROACH
}

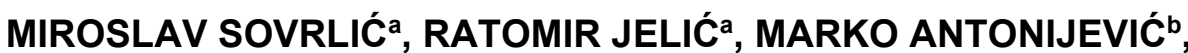 \\ ZORAN MARKOVIĆ ${ }^{b}$, JOVICA TOMOVIĆ ${ }^{a *}$, EMINA MRKALIĆ
}

\begin{abstract}
The interactions between human serum albumin (HSA) and haloperidol (HPD) in the presence or absence of caffeine (CAF) with HSA were studied by fluorescence-absorption spectroscopy and molecular modeling. The results showed that the presence of CAF decreased binding constants of HPDHSA with increasing temperature from $1.07 \times 10^{4} \mathrm{~mol} / \mathrm{dm}^{3}$ to $3.13 \times 10^{2} \mathrm{~mol} / \mathrm{dm}^{3}$. The results indicate that the HSA-HPD and HSA-CAF-HPD system is very thermally sensitive. The number of binding sites obtained at three different temperatures were close to 1 indicating the presence of one binding site of HPD, CAF on HSA. Fluorescence quenching was initiated by dynamic quenching procedure irrespective of the absence or presence of CAF. The negative value of the free energy change $(\Delta G)$ indicates a spontaneous binding process of both, HPD to HSA protein and HPD to the HSA-CAF protein complex. The values of $\Delta H^{0}<0$ and $\Delta S^{0}<0$ for binding interaction HSA-HPD and HSA-CAF$\mathrm{HPD}$, indicate that interaction is enthalpy driven. Docking simulation results are confirmed that the most preferable place for binding HPD and CAF is the active site I, in domain II subdomain IIA. The present study suggested that the combined actions of HPD and CAF, may lead to further changes in HSA conformation.
\end{abstract}

Keywords: Caffeine; Interaction; Human serum albumin; Haloperidol; Fluorescence;

\section{INTRODUCTION}

Within plasma proteins, human serum albumin (HSA) is undoubtedly the most important transporter of drugs and other small molecules. HSA accounts for about $60 \%$ of the proteins present in the plasma of healthy

a University of Kragujevac, Faculty of Medical Sciences, Department of Pharmacy, Svetozara Markovića 69, Kragujevac 34000, Serbia

b University of Kragujevac, Institute for Information Technologies, Department of Science, Jovana Cvijića bb, Kragujevac 34000, Serbia

Corresponding author: jovicatomovic2011@gmail.com 
MIROSLAV SOVRLIĆ, RATOMIR JELIĆ, MARKO ANTONIJEVIĆ, ZORAN MARKOVIĆ, JOVICA TOMOVIĆ, EMINA MRKALIĆ

individuals. It is smaller in mass $(66,500 \mathrm{Da})$ than other plasma proteins [1]. Binding to HSA is often very specific, at least for low or therapeutic drug concentrations. Two binding sites in HSA, sites I and II, by Gail Sudlow classification and co-workers, are involved in tying up a large number class of compounds. Analysis of the crystal structure of albumin revealed that the two major binding sites of the hydrophobic cavity in subdomains IIA and IIIA [2].

Caffeine (CAF) is the most widely consumed psychoactive substance in the world and can be found in coffee seeds (2\%), cola cotyledons (up to $3 \%$ ), and in tea leaves (up to 4\%) [3]. It is purine alkaloid that posses many different pharmacological effects such as: stimulation of the central nervous system, diuretic effect, a stimulating effect on the heart, muscle relaxation, stimulation of gastric secretion, etc. $[3,4]$. CAF binds to plasma proteins in a certain percentage (10-30\%). Caffeine could bind to HSA via the hydrophobic interaction between the pyrimidine ring and aromatic stacking. The binding is carried out via 3 methyl groups by Van der Waals forces and hydrogen bonding [5]. The primary binding site was considered to be a hydrophobic cavity formed by Leu198, Lys199, Ser202, Phe211, Trp214, Val344, Ser454 and Leu481 in domain Ila, Sudlow's site I [6].

Haloperidol (HPD) is an antipsychotic drug from the group of butyrophenones which competitively blocks postsynaptic dopamine (D2) receptors in the mesolimbic system of the brain, thereby eliminating dopamine neurotransmission which is beneficial in patients with psychoses and delusions [7]. It is highly bound to plasma proteins (90\%). Haloperidol is used extensively for the treatment of psychotic disorders, therefore monitoring of plasma haloperidol concentrations is clinically significant. The potential severity of the side effects is one of the reasons for monitoring the concentration of haloperidol in the blood [8]. Earlier binding experiments with HPD and HSA indicated that the binding site was located in a hydrophobic cavity near Sudlow's site I (subdomain IIA) [9,10].

Given that the actual volume of distribution and drug concentration at the receptor-binding site are associated with the amount of unbound fraction of the drug, the complete characterization of the mechanism of drug binding to plasma proteins became a necessary step for understanding the pharmacokinetic, pharmacodynamic and the toxicological profile of each drug [11]. Simultaneous administration of the two drugs may lead to competition at the level of binding to HSA, which may significantly affect the disposition of both drugs, with possible serious physiological consequences. Due to its characteristics, HSA is a unique protein model for the quantitative and qualitative study of proteindrug interactions [12]. Previous studies showed that CAF as well as other natural products present in food and beverages could have an effect on binding parameters of different drugs to HSA [13-15]. 
INFLUENCE OF THE CAFFEINE ON THE INTERACTION BETWEEN HALOPERIDOL ...

The aim of this study is to systematically characterize the interactions of HPD and CAF with HSA using spectroscopic and molecular modeling methods. The thermodynamic parameters, nature of forces responsible for drug binding and location of the probe in macromolecular architecture were discussed based on the results of temperature variation experiments as well as molecular docking results.

\section{RESULTS AND DISCUSSION}

\section{Interaction mechanism of HSA-HPD and HSA-CAF-HPD}

In order to demonstrate the binding of HPD and CAF to HSA, the fluorescence emission spectra of HSA were recorded. Fluorescence spectroscopy methodology is used to test small molecule binding for proteins. This test method can provide information on the binding mechanism, binding mode, binding constant, and number of binding sites [16]. The interaction of several antipsychotic drugs with serum albumin has been studied in the past $[17,18]$. Also, in previous studies has been shown that natural compounds from food and beverages can modulate interaction between HSA and antipsychotics [19]. However, a detailed analysis of interactions between HSA and HPD in the presence or absence of CAF is not available in the literature. The fluorescence spectra of HSA with different concentrations of HPD and same concentration CAF were recorded at temperatures 293, 303 and $310 \mathrm{~K}$. Based on numerous papers, we can conclude that Trp213 residues are major drug targets in HSA [20]. The tryptophan (Trp) fluorescence intensity of HSA decreases continuously with the regular addition of raising concentration of HPD, indicating that HPD is interacting with HSA (Figure 1.-left). The interaction of HPD with HSA in the presence of a competitive compound was investigated (Figure 1.-right). It is clear that fluorescence intensity is significantly reduced in the presence of different HPD concentrations and fixed CAF concentrations at all recorded temperatures compared to the emission spectra recorded without CAF. The binding of HPD-induced a redshift in the fluorescence emission spectrum of HSA indicating that the polarity around the Trp213 was increased in the presence of HPD. In the presence of CAF, the binding of HPD also induced a redshift in fluorescence emission spectrum of the HSA-HPD complex, indicating that binding of CAF further increased the polarity around HPD bound to HSA. This was probably due to the loss of the compact structure of the hydrophobic subdomain IIA where Trp is located [21]. The presence of a red or blue shift $\lambda_{\max }$ indicates that there was a decrease or increase in the hydrophobicity of the microenvironment of the binding region of the drug. 
MIROSLAV SOVRLIĆ, RATOMIR JELIĆ, MARKO ANTONIJEVIĆ, ZORAN MARKOVIĆ, JOVICA TOMOVIĆ, EMINA MRKALIĆ
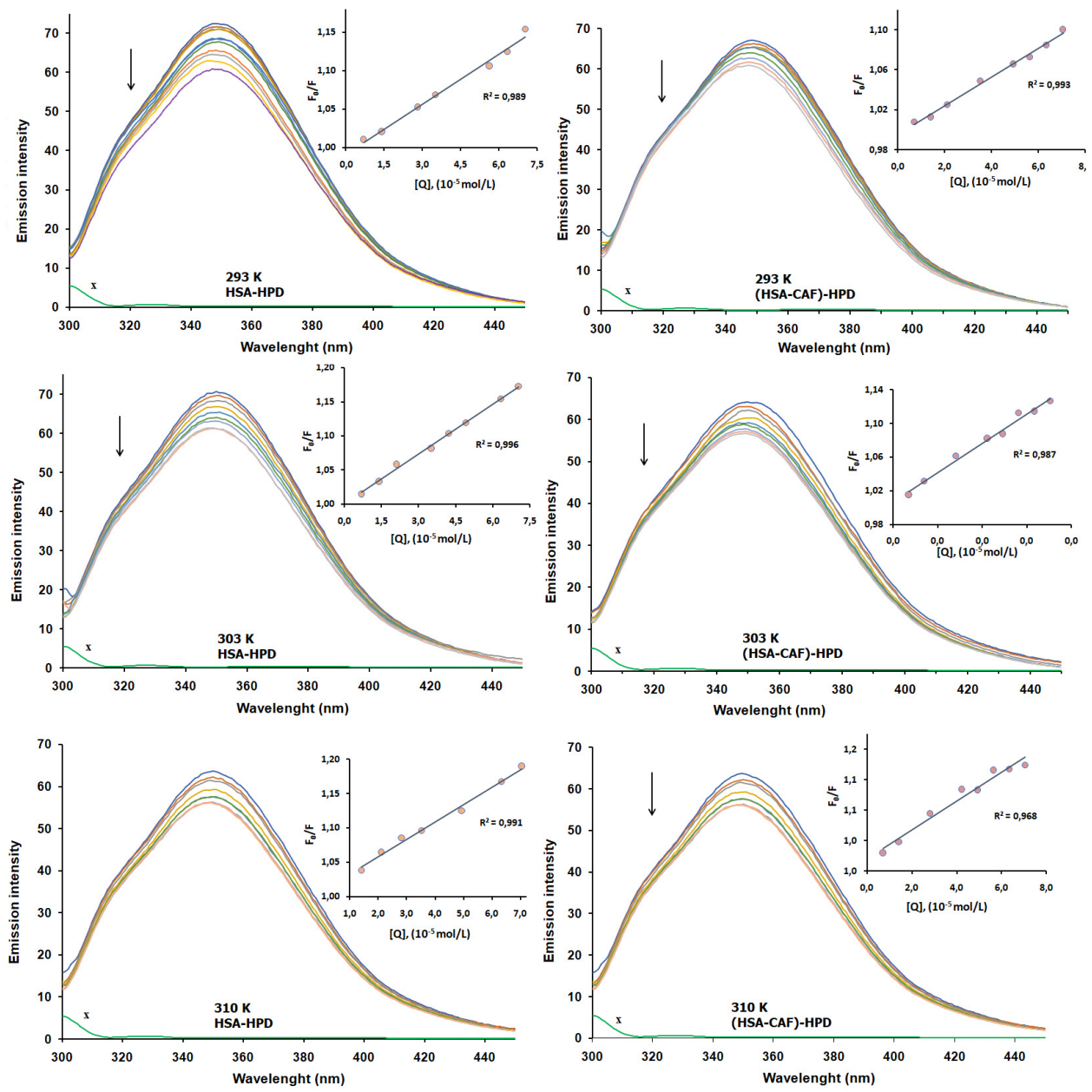

Figure 1. Fluorescence emission spectra and Stern-Volmer plots of the fluorescence quenching of HSA fluorescence with HPD (left) and HSA-CAF-HPD complex (right) (increasing concentration HPD along the arrow direction) at different temperatures. Curve $x$ shows the emission spectrum of HPD only.

Fluorescence quenching data obtained at different temperatures is usually described by Stern-Volmer (SV) equation (1) [22]:

(1) $F_{0} / F=1+k_{q} \times \tau_{0}[Q]=1+K_{D}[Q]=1+K_{S V}$ 
where $F_{0}$ and $F$ are the fluorescence intensities of HSA in the absence and presence of the quencher, respectively, [Q] is the concentration of the quencher, $K_{D}$ is the quenching constant, $k_{q}$ is the quenching rate constant of biological macromolecule, $\mathrm{T}_{0}$ is the average lifetime of the molecule without any quencher and the fluorescence lifetime of the biopolymer is $10^{-8} \mathrm{~s}$. $\mathrm{K}_{\mathrm{sv}}$ and $\mathrm{k}_{\mathrm{q}}$ values are given in Table 1. Given that in our experiments, te concentration of free HPD was not known, we took approximately corresponds to the total concentration of HPD.

Quenching can be defined as a decrease of fluorescence and under the conditions of fixed $\mathrm{pH}$, temperature, and ionic strength. Fluorescence quenching can occur by a variety of mechanisms, most commonly classified as static and dynamic quenching. These mechanisms can be distinguished by their differing dependence on temperature and viscosity. This also means that only one type, either dynamic (interaction of the excited fluorophore with the quencher) or static (fluorophore and quencher interact in the ground state), mechanism of quenching occurs [23]. Basically, albumin-drug interaction is a dynamic and reversible process, and dissociation of bound drug molecules from the albumin-drug complex occurs very quickly, probably within a few milliseconds or in a shorter period of time [20].

Fluorescence data can also be used to calculate a constant of binding $\left(\mathrm{K}_{\mathrm{a}}\right)$ and number of binding sites $(\mathrm{n})$. When small molecules bind independently to a set of equivalent sites on a macromolecule, a balance between free and bound the molecule can be represented by modified Stern-Volmer equation (2) to confirm the mechanism [24].

(2) $\log \frac{F_{0}-F}{F}=\log K_{a}+n \log [Q]$

where $K_{a}$ is the binding constant and $n$ is the number of binding sites. There are many binding sites per HSA molecule and $[\mathrm{K}]$ is the concentration of quenchers. Values $\mathrm{K}_{\mathrm{a}}$ and $\mathrm{n}$ are obtained from the intersection and slope of the graph of the dependence of $\log \left(\mathrm{F}_{0}-\mathrm{F}\right) / \mathrm{F}$ on log $[\mathrm{K}]$ (Figure 2). The values of $K_{a}$ and $n$ are given in Table 1. From Figure 2, it was known that under certain HPD concentrations, the curves of $F_{0} /\left(F_{0}-F\right)$ versus $1 /[Q]$ were linear. 
MIROSLAV SOVRLIĆ, RATOMIR JELIĆ, MARKO ANTONIJEVIĆ, ZORAN MARKOVIĆ, JOVICA TOMOVIĆ, EMINA MRKALIĆ

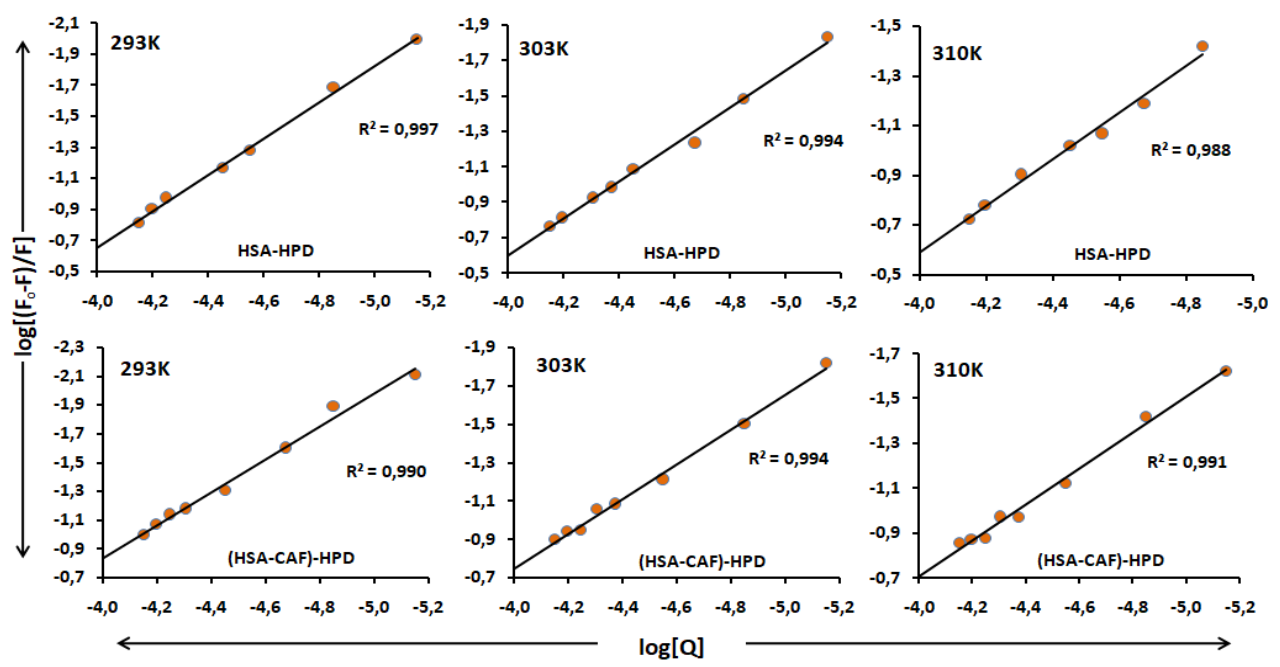

Figure 2. Modified Stern-Volmer Plots of $\log \left(F_{0}-F\right) / F$ versus log [Q] at different temperatures using equation 2.

\section{The binding constants $\left(K_{a}\right)$ and the number of binding sites (n)}

The values of $n$ obtained at three different temperatures were close to 1 indicating the presence of one binding site of HPD on HSA and HSACAF. In addition, an increase in temperature leads to an decrease in the (n) binding capacity of HSA for HPD and 1.17 values were obtained; 1.04 and 0.93 at 293, 303 and $310 \mathrm{~K}$. Also, the values of $n$ were decreased in the presence of $\mathrm{CAF}$ at all temperatures. Our report is an excellent agreement with the previous reports where antipsychotic drugs have shown to bind with HSA at one binding site [9]. Results from our study indicate that the binding of HPD at sites to HSA and HSA-CAF was a concentration-dependent saturable process.

Correlation coefficients above 0.9 indicate a good linear relationship. It is clear from Figure 1. and Table 1 that the values of $K_{a}$ were decreased significantly upon an increase in the temperature indicating that the complex between HSA and HPD gets disrupted on increasing the temperature. Binding constant decreases with increasing temperature, both in the absence and in the presence of CAF. The value of quenching constant obtained for HSAHPD interaction was in the range from $1.07 \times 10^{4}$ to $1.48 \times 10^{3} \mathrm{~mol} / \mathrm{dm}^{3}$, while the value of quenching for HSA-CAF-HPD was in the range $5.47 \times 10^{3}$ to $3.13 \times 10^{2} \mathrm{~mol} / \mathrm{dm}^{3}$, at three different temperatures. These results indicate that the HSA-HPD and HSA-CAF-HPD system is very thermally sensitive. In other words, even a small temperature change can lead to significant changes in the $\mathrm{K}_{\mathrm{a}}$ value. The unstable compound would be partly decomposed with the rising temperature, therefore, the values of $K_{a}$ decreased. As a rule, the 
$\mathrm{K}_{\mathrm{sv}}$ values increase with an increase in temperature for dynamic quenching, and the Kq values were on the order of $10^{11} \mathrm{~L} / \mathrm{mol} \cdot \mathrm{s}$. These results can be explained by more collisions between drug and fluorophores and faster diffusion at higher temperatures [25-26].

Based on the conventional concept, the cellular uptake is proportional to the unbound fraction of the drug. If a drug is weaker bound to serum albumins, the fraction of free drug available to act on target tissues may be significantly increased and the effect of the drug may consequently be higher [27]. The data indicate that the binding of HPD to HSA was largely inhibited in the presence of CAF. This may be explained by the competitive interference of HPD and CAF in the vicinity of the binding site of HSA which leads to increasing concentrations of free HPD in the plasma and its maximum effect [28]. Further, te mechanism by which CAF decreased the binding affinity and led to a decrease in the binding constant is not sufficiently elucidated, but indicates that probably there is a competition between CAF and HPD for binding to HSA.

The results presented in Table 1 indicate that the stability of the HSAHPD complex decreases with increasing temperature and that HPD is better bound and transported by HSA at lower temperatures as well as due to the absence of CAF. All these results showed that there were obviously characters of dynamic quenching.

Table 1. The interaction parameters of the HSA-HPD and HSA-CAF-HPD systems at different temperatures

\begin{tabular}{|c|c|c|c|c|c|c|}
\hline Systems & $\mathrm{T} / \mathrm{K}$ & $\mathrm{Ksv} / \mathrm{dm}^{3} \mathrm{~mol}^{-1}$ & $\mathrm{Kq} / \mathrm{dm}^{3} \mathrm{~mol}^{-1} \mathrm{~s}$ & $\mathrm{~K} / \mathrm{dm}^{3} \mathrm{~mol}^{-1}$ & $\mathrm{n}$ & $\mathrm{R}$ \\
\hline \multirow{3}{*}{ HSA-HPD } & 293 & $2.17 \times 10^{3}$ & $2.17 \times 10^{11}$ & $1.07 \times 10^{4}$ & 1.171 & 0.997 \\
\cline { 2 - 7 } & 303 & $2.43 \times 10^{3}$ & $2.43 \times 10^{11}$ & $3.72 \times 10^{3}$ & 1.042 & 0.994 \\
\cline { 2 - 7 } & 310 & $2.54 \times 10^{3}$ & $2.54 \times 10^{11}$ & $1.48 \times 10^{3}$ & 0.939 & 0.988 \\
\hline \multirow{3}{*}{ HSA-CAF-HPD } & 293 & $1.44 \times 10^{3}$ & $1.44 \times 10^{11}$ & $5.47 \times 10^{3}$ & 1.143 & 0.990 \\
\cline { 2 - 7 } & 303 & $1.74 \times 10^{3}$ & $1.74 \times 10^{11}$ & $7.48 \times 10^{2}$ & 0.905 & 0.994 \\
\cline { 2 - 7 } & 310 & $1.90 \times 10^{3}$ & $1.90 \times 10^{11}$ & $3.13 \times 10^{2}$ & 0.800 & 0.991 \\
\hline
\end{tabular}

The decreasing trend of $\mathrm{K}_{\mathrm{a}}$ with increasing temperature indicates that the HPD binding reaction for HSA was exothermic, both in the presence and in the absence of CAF [29].

\section{UV-Vis measurements}

In this part of the study, we examined changes in the UV absorption spectra of the HPD, HSA-CAF, and HSA-CAF-HPD systems, with varying concentrations of haloperidol. The contribution of HPD and competing for CAF was subtracted from the results in complexes. HSA has a weak absorption 
MIROSLAV SOVRLIĆ, RATOMIR JELIĆ, MARKO ANTONIJEVIĆ, ZORAN MARKOVIĆ, JOVICA TOMOVIĆ, EMINA MRKALIĆ

maximum at about $278 \mathrm{~nm}$ due to the cumulative absorption of three aromatic amino acid residues (Trp, Tyr and Phe). The absorption spectra of HPD are characterized by an absorption peak at $247 \mathrm{~nm}$. The absorption maximum at $278 \mathrm{~nm}$ slightly increased (Figure 3 ), which was largely caused by $\pi-\pi$ * transitions of aromatic amino acid residues to HSA [30], indicating that a complex has formed between HSA and CAF and HSA-CAF and HPD. At the characteristic peak for haloperidol $(247 \mathrm{~nm})$ we notice that with increasing concentration of HPD, the absorption intensity of HSA-CAF increasing (Figure 3; inset), while the concentration of CAF remained the same, suggesting that we can exclude static quenching mechanism interactions between HSA$\mathrm{CAF}$ and HPD. The dynamic quenching only affects the excited states of the fluorophores and, thus, no changes in the absorption spectra are expected. However, the ground state complex formation will result in perturbation of the absorption spectrum of the fluorophore [23]. We also found a similar phenomenon observed with the fluorescence method. It is evident from UV-Vis spectral results that the progressive increase of absorbance with the increase in drug concentration confirms the formation of new protein-drugdrug complexes (HSA-CAF-HPD).

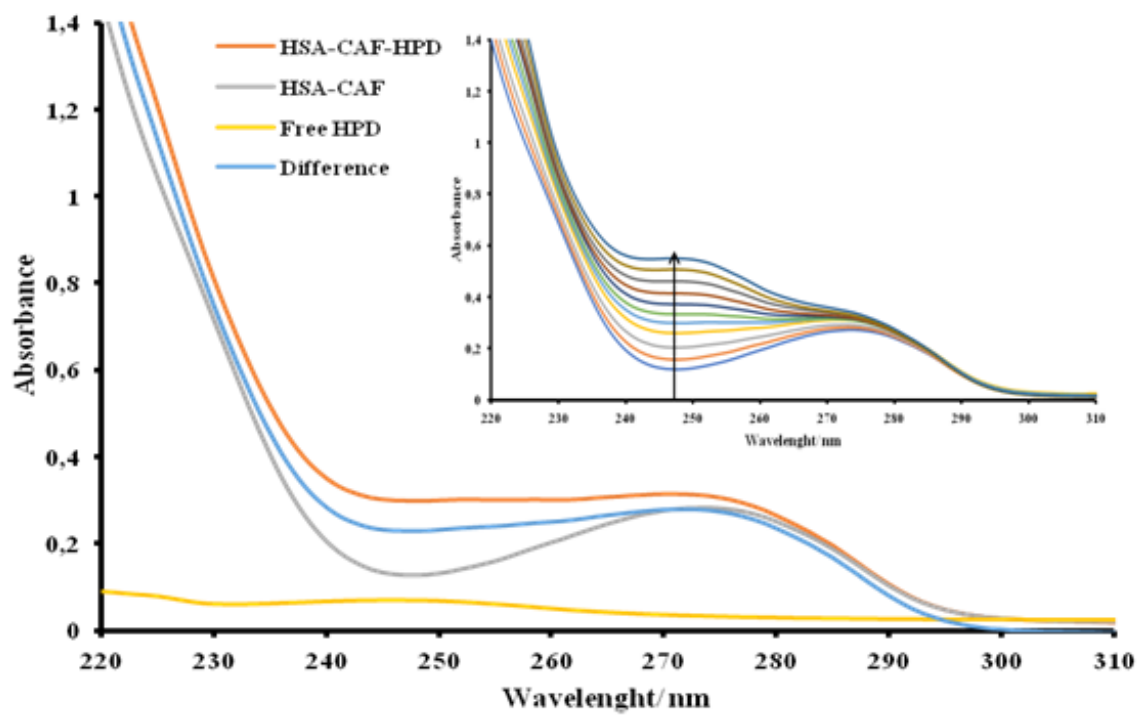

Figure 3. UV-Vis absorption spectra of HSA-CAF; absorption spectrum of HPD only; absorption spectrum of HSA-CAF-HPD complex; difference between absorption spectrum of HSA-CAF-HPD complex and free HPD. Inset: UV-Vis absorption spectra of HSA-CAF (1:1) in the presence of increasing amounts of HPD from 0.0 to $7.0 \times 10^{-5} \mathrm{~mol} \mathrm{dm}^{-3}(\mathrm{~T}=298 \mathrm{~K}, \mathrm{pH}=7.4)$. 


\section{Thermodynamics of HSA-HPD and HSA-CAF-HPD interaction}

There are essentially four types of non-covalent interactions that could play a role in ligand binding to proteins. These are electrostatic interaction, hydrogen bond formation, van der Waals interaction, hydrophobic and steric contacts [31]. To identify the binding force between HPD and HSA, and HPD to HSA-CAF complex, an examination of the binding was carried out at three different temperatures 293,303 and $310 \mathrm{~K}$. To find out the nature of the interaction of HPD with HSA and HPD with HSA-CAF complex, thermodynamic parameters (enthalpy change $\left(\Delta H_{0}\right)$ entropy change $\left(\Delta S_{0}\right)$ and Gibbs free energy change $(\Delta G 0)$ ), were calculated using Van't Hoff and Gibbs-Helmholtz relations [32] using equation (3) and equation (4):

(3) $\ln K_{a}=-\Delta H^{0} / R T+S^{0} / R$

(4) $\Delta G^{0}=\Delta H^{0}-T \Delta S^{0}$

where $\mathrm{K}_{\mathrm{a}}$ is the binding constant at the appropriate temperature, $\mathrm{R}$ is the gas constant and $\mathrm{T}$ is absolute temperature (Figure 4). The values of $\Delta \mathrm{H}^{0}, \Delta \mathrm{S}^{0}$ and $\Delta \mathrm{G}^{0}$ at different temperatures are shown in Table 2 . The negative value of the free energy change $(\Delta G)$ indicates a spontaneous (exergonic) binding process of both, HPD to HSA protein and HPD to HSA-CAF protein complex [33]. The values of $\Delta H^{0}<0$ and $\Delta S^{0}<0$ for binding interaction HSA-HPD and HSA-CAF-HPD, means that interaction is enthalpy driven. It can be seen that the binding reactions of these components are exothermic and are characterized by relatively large negative $\Delta \mathrm{H}$ values. In this case, a spontaneous reaction is dependent upon the $T \Delta S$ term being small relative to the $\Delta \mathrm{H}$ term, so that $\Delta \mathrm{G}$ is negative [34,35]. The latter is consistent with dispersive van der Waals interactions of aromatic chromophores being the main contributors to bind formation. Dispersive van der Waals interactions are characterized both by negative enthalpy and negative entropy indicating an enthalpic origin for the binding process of these drugs to HSA protein [36].

Table 2. Thermodynamic parameters of the HSA-HPD and HSA-CAF-HPD systems at different temperatures

\begin{tabular}{|c|c|c|c|c|}
\hline \multirow{2}{*}{ System } & $\mathrm{T} / \mathrm{K}$ & $\Delta \mathrm{H}^{0} / \mathrm{kJ} \mathrm{mol}^{-1}$ & $\Delta \mathrm{S}^{0} / \mathrm{J} \mathrm{mol}^{-1} \mathrm{~K}^{-1}$ & $\Delta \mathrm{G}^{0} / \mathrm{kJ} \mathrm{mol}^{-1}$ \\
\hline \multirow{3}{*}{$\mathrm{HSA}-\mathrm{HPD}$} & 293 & & & -22.70 \\
\cline { 2 - 5 } & 303 & -87.15 & -219.88 & -20.50 \\
\cline { 2 - 5 } & 310 & & & -18.96 \\
\hline \multirow{3}{*}{$(\mathrm{HSA}-\mathrm{CAF})-H P D$} & 293 & & -368.56 & -17.13 \\
\cline { 2 - 5 } & 303 & -128.86 & & -14.55 \\
\cline { 2 - 5 } & 310 & & & \\
\hline
\end{tabular}


MIROSLAV SOVRLIĆ, RATOMIR JELIĆ, MARKO ANTONIJEVIĆ, ZORAN MARKOVIĆ, JOVICA TOMOVIĆ, EMINA MRKALIĆ

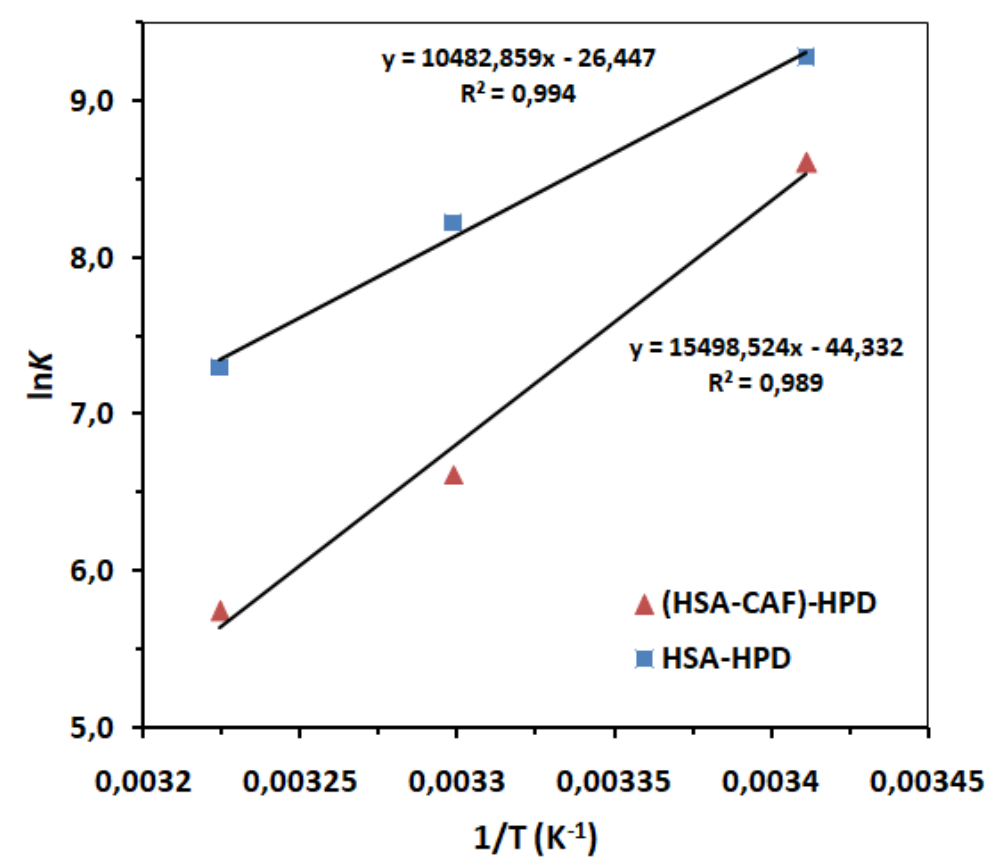

Figure 4. Van't Hoff plot of the interaction between HSA and HPD, and HSA-CAF complex and HPD, T $=293,303$, and $310 \mathrm{~K}$.

\section{Docking studies}

The HSA protein is able to bind multiple molecules in six active binding sites [37-38]. In most cases, drugs are binding to sites I and II, because these sites have the highest binding affinities [37]. The reason for this is a high amount of different amino acid residues that are forming hydrophobic cavities inside subdomain IIA and IIIA where those active sites are found. The experimental work in this paper has shown that active site, which has the highest affinity for binding the HPD, is the same active site where CAF molecules are banded, alongside with other drugs like warfarin [9]. The AGFR software was employed for finding the active site by configuring and computing affinity maps for a receptor molecule (Figure 5). Obtained maps are further used in AutoDock4 for docking simulation. Docking simulation results are confirmed that the most preferable place for binding HPD and CAF is the active site I (Sudlow I) in domain II subdomain IIA (Figure 5). 


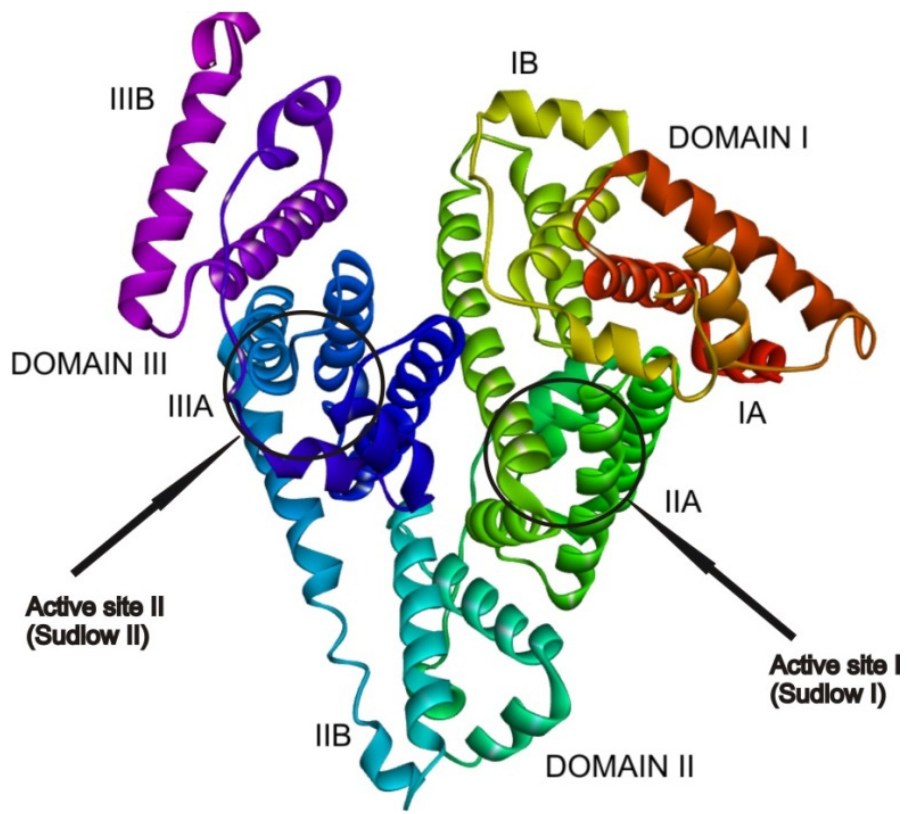

Figure 5. Active sites, domains and subdomains of HSA.

The presented results in Table 3 contain values of Gibbs energies, inhibition constants, and other thermodynamic parameters that describe the binding of HPD and CAF molecules to HSA, as well as binding of these molecules to HSA-HPD and HSA-CAF complexes.

Table 3. Estimated values of binding energies for HSA with HPD and CAF

\begin{tabular}{|l|c|c|c|c|c|c|c|}
\hline Conformations & $\begin{array}{c}\Delta \mathbf{G}_{\text {ind }} \\
\left(\mathrm{kJ} \mathrm{mol}^{-1}\right)\end{array}$ & $\begin{array}{c}\mathrm{K}_{\mathrm{i}} \\
(\mu \mathrm{M})\end{array}$ & $\begin{array}{c}\Delta \mathbf{G}_{\text {inter }} \\
\left(\mathrm{KJ} \mathrm{mol}^{-1}\right)\end{array}$ & $\begin{array}{c}\left.\Delta \mathbf{G}_{v d \text { w }}\right) \\
+ \text { desol } \\
\left(\mathrm{kJ} \mathrm{mol}^{-1}\right)\end{array}$ & $\begin{array}{c}\Delta \mathbf{G}_{\text {ele }} \\
\left(\mathrm{kJ} \mathrm{mol}^{-1}\right)\end{array}$ & $\begin{array}{c}\Delta \mathbf{G}_{\text {total }} \\
\left(\mathrm{kJ} \mathrm{mol}^{-1}\right)\end{array}$ & $\begin{array}{c}\Delta \mathbf{G}_{\text {tor }} \\
\left(\mathrm{kJ} \mathrm{mol}^{-1}\right)\end{array}$ \\
\hline HSA-HPD & -40.7 & 0.08 & -43.2 & -42.8 & -0.38 & -6.19 & 8.74 \\
\hline HSA-CAF-HPD & -39.8 & 0.11 & -44.6 & -43.9 & -0.71 & -3.93 & 8.74 \\
\hline HSA-CAF & -20.8 & 231.7 & -20.8 & -20.7 & -0.04 & 0.00 & 0.00 \\
\hline
\end{tabular}

As can be seen from Table 3, the obtained thermodynamic parameters from docking simulations are following the same trend that is established by the experiment (Table 2). The values of Gibbs energy from the docking calculation are equally lower in relation to the experimental values from Table 2 . That partially can be explained by higher entropy values 
MIROSLAV SOVRLIĆ, RATOMIR JELIĆ, MARKO ANTONIJEVIĆ, ZORAN MARKOVIĆ, JOVICA TOMOVIĆ, EMINA MRKALIĆ

in the experiment, solvent presence, and the usage of approximations in the equations for theoretical calculations, for example, the usage of the compact unbounded model.

It should be noted that the presence of CAF in the blood inhibits the binding of HPD. The reason for this lies in the fact that both molecules are binding in the same active place. It was found that there is a small difference in binding energy, which cannot be ignored if HPD binds only to HSA and / or to HSA-CAF complex (see values of binding constants Table 3 ).

\section{CONCLUSIONS}

In this paper, fluorescence-absorption spectroscopy and molecular modeling were used to investigate the interaction between HSA and HPD under simulative physiological conditions (in vitro) in the presence of CAF. $\mathrm{CAF}$ is an important phytonutrient, which if used with other drugs may cause interference. The presence of CAF, caused a decrease in the binding constants of the HPD with HSA (competitive interference), because CAF and HPD have almost the same binding site in HSA. This fact indicates that in the presence of caffeine there may be an increase in the free fraction of haloperidol in plasma, which may lead to the manifestation serious side effects or changes in effectiveness. In order to reduce side effects, the patience under HPD treatment should reduce their intake of beverages rich in CAF. This research illustrates that the simultaneous uptake of coffe, tea, ...etc and drugs may cause interaction.

\section{EXPERIMENTAL SECTION}

\section{Reagents and chemicals}

CAF (Ph.Eur.-USP-FU, catalog No. 326356) was obtained commercially from the Carlo Erba reagents. HPD with purity over $95 \%$ (Product No. H1512), HSA (Lyophilized powder $\geq 96 \%$ by agarose gel, essentially fatty acid free, product No. A1887) and phosphate-buffered saline (PBS, Product No. P4417) were purchased from Sigma-Aldrich Chemical Company (St. Louis, MO, USA). All chemicals are used without further purification. Double-distilled water was used throughout the experiment.

\section{Preparation of solutions}

Solution of PBS $(0.01 \mathrm{M})$ contains $0.0027 \mathrm{M} \mathrm{KCl}$ and $0.137 \mathrm{M} \mathrm{NaCl}$, $\mathrm{pH}=7.4$ at $298,15 \mathrm{~K}$, was prepared by dissolving one tablet in $200 \mathrm{ml}$ of distilled water. HSA stock solution $\left(2 \cdot 10^{-5} \mathrm{M}\right)$ was prepared by dissolving 
them in PBS. The stock solution of HPD $\left(3.2 \cdot 10^{-3} \mathrm{M}\right)$ was prepared by dissolving them in $5 \%$ methanol and then diluted to $2.82 \cdot 10^{-4} \mathrm{M}$ with solution of PBS. The CAF $\left(2 \cdot 10^{-4} \mathrm{M}\right)$ stock solutions were dissolved in $5 \%$ ethanol and diluted with solution of PBS. All solutions were made fresh and stored in the refrigerator at $4{ }^{\circ} \mathrm{C}$ prior to use.

\section{Fluorescence spectra measurements}

All fluorescence spectra were measured on an RF-1501 PC spectrofluorometer (Shimadzu, Japan) with excitation at $295 \mathrm{~nm}$, using a 150 W Xenon lamp source, $1.0 \mathrm{~cm}$ quartz cells and a thermostatic bath. Fluorescence spectra were recorded at $293,303,310 \mathrm{~K}$ in the range of $310-460 \mathrm{~nm}$. The widths of the excitation and emission slit widths were both fixed at $5 \mathrm{~nm}$. The specified temperatures were controlled by Julabo ED (v.2) open circulating bath (Julabo Labortechnik GmbH, Germany).

The fluorescence spectra were obtained with constant HSA concentration $\left(2.0 \times 10^{-6} \mathrm{M}\right)$ and by varying the HPD concentrations from 0 to $7.0 \times 10^{-5} \mathrm{M}$ for HSA-HPD binary system. For the research on the effects of the CAF on the HSA-HPD system fluorescence spectra were also recorded at different temperatures $(293,303$ and $310 \mathrm{~K})$. In all series of solutions, the molar ratio of HSA to CAF is maintained at $1: 1\left(2 \cdot 10^{-6} \mathrm{M}\right)$. The solutions of HSA-CAF were left to stand for an hour, and then in the all of the solutions concentration of HPD varied from 0 to $5 \cdot 10^{-5} \mathrm{M}$. Resultant mixtures were incubated at different temperatures for half an hour, respectively.

\section{Ultra-violet spectroscopy}

All absorption maxima of the spectra were recorded in the range of 200 to $400 \mathrm{~nm}$ at a temperature of $298 \mathrm{~K}$ on a spectrophotometer (Agilent Cary 300 spectrophotometer equipped with $1.0 \mathrm{~cm}$ quartz cells). On the ordinate, the detection of absorbance values in the range from 0 to 3 was set. The scanning speed was set to $480 \mathrm{~nm}$ per minute, and the device entered values of absorbance at $1 \mathrm{~nm}$. Before each new batch, a pure solution corresponding to the buffer was recorded, and the obtained absorption spectrum formed the baseline. Enabling the baseline correction option, the program corrected all recorded spectra by subtracting the values corresponding to the baseline. The absorption spectra were obtained with constant HSA and CAF concentrations $\left(2.0 \times 10^{-6} \mathrm{~mol} \mathrm{dm}^{-3}\right)$ and by varying the HPD concentrations from 0.0 to $7.0 \times 10^{-5} \mathrm{~mol} \mathrm{dm}^{-3}$. 
MIROSLAV SOVRLIĆ, RATOMIR JELIĆ, MARKO ANTONIJEVIĆ, ZORAN MARKOVIĆ, JOVICA TOMOVIĆ, EMINA MRKALIĆ

\section{Molecular docking}

The molecular docking simulations were employed in order to better understand the inhibitor efficiency of the investigated compounds. Before molecular docking simulations, the pockets and binding sites of HSA protein were determined. AutoGridFR (AGFR) program [39] was used for this purpose. Ligands were prepared for docking by optimizing their geometries using the density functional theory (DFT) and employing B3LYP functional $[40,41]$ that is implemented in the Gaussian 09W software package [42]. The crystal structure of HSA was obtained from the Brookhaven Protein Data bank (PDB ID:1HK1, [43]). Protein was prepared for docking in Discovery Studio 4.0 [44]. Polar hydrogen atoms, Kollman charges, and other parameters were added using the graphical interface from AutoDockTools (ADT) [45]. The AutoDock 4.2 software was used for molecular docking simulations. In the docking procedure, ligands are presented as flexible molecules and the docking software was free to rotate all single bonds to catch the best position inside the active site of HSA. The Lamarckian Genetic Algorithm (LGA) was used for protein-ligand and complex-ligand flexible docking. The conformer with the lowest binding energy was used for further analyses. Parameters for the LGA method were determined as follows: a maximum number of energy evaluations was 250.000 , a maximum number of generations was 27,000 , and mutation and crossover rates were 0.02 and 0.8 , respectively. Algorithms, that AutoDock 4.2 software is based on, can predict positions within the protein target, for the ligand, and to assess them by scoring functions defined by setting the grid box. Grid box with dimensions $56 \times 50 \times 58 \AA^{3}$ in $-x,-y$, and $-z$ directions of HSA was used to cover the protein binding site and accommodate ligand to move freely. A gridpoint spacing of $0.375 \AA$ was used for auto grid runs. Results of the interactions between the target protein and investigated compounds were analyzed and illustrated in Discovery Studio 4.0 and AutoDockTools.

\section{ACKNOWLEDGMENTS}

This work was supported by the Ministry of Education, Science and Techological Development of the Republic of Serbia (Agreement No. 45103-68/2020-14/200122) 
INFLUENCE OF THE CAFFEINE ON THE INTERACTION BETWEEN HALOPERIDOL ...

\section{REFERENCES}

1. T. Peters Jr.; All about albumin: biochemistry, genetics, and medical applications, 1st ed; San Diego: Academic press, 1995; pp. 382

2. F. Yang; Y. Zhang; H. Liang; Int. J. Mol. Sci., 2014, 15, 3580-3595.

3. I. Jerković; C.I. Tuberoso; P.M. Kuś; Z. Marijanović; M. Kranjac; RSC Adv., 2014, 4, 60557-60562.

4. A. Adan; J.M. Serra-Grabulosa; Hum. Psychopharm. Clin., 2010, 25, 310-317.

5. Q. Wu; C. Li; Y. Hu; Y. Liu; Sci. China. Ser. B Chem., 2009, 52, 2205-2212.

6. W. Wang; W. Zhang; Y. Duan; Y. Jiang; L. Zhang; B. Zhao; P. Tu; Spectrochim. Acta. A Mol. Biomol. Spectrosc., 2013, 115, 57-63.

7. S. Miyamoto; G.E. Duncan; C.E. Marx; J.A. Lieberman; Mol. Psychiatry., 2005, 10, 79-104.

8. S. Kudo; T. Ishizaki; Clin. Pharmacokinet., 1999, 37, 435-456.

9. J.D. Berić; S.D. Stojanović; E.M. Mrkalić; Z.D. Matović; D.R. Milovanović; M.M. Sovrlić; R.M. Jelić; Monatsh. Chem., 2018, 149, 2359-2368.

10. C.P. de Morais e Coura; E.T. Paulino; C.M. Cortez; V.M. da Silva Fragoso; Serum albumin and the haloperidol pharmacokinectics. A study using a computational model. AIP Publishing LLC, 2016, p. 100009.

11. S. Schmidt; D. Gonzalez; H. Derendorf; J. Pharm. Sci., 2010, 99, 1107-1122.

12. O. Dömötör; C.G. Hartinger; A.K. Bytzek; T. Kiss; B.K. Keppler; E.A. Enyedy; J. Biol. Inorg. Chem., 2013, 18, 9-17.

13. Y.Q. Wang; H.M.Zhang; Q.H. Zhou; Eur. J. Med. Chem., 2009, 44, 2100-2105.

14. D. Raghav; S. Mahanty; K. Rathinasamy; Spectrochim. Acta. A Mol. Biomol. Spectrosc., 2020, 226, 117584.

15. M.M. Islam; V.K. Sonu; P.M. Gashnga; N.S. Moyon; S. Mitra; Spectrochim. Acta. A. Mol. Biomol. Spectrosc., 2016, 152, 23-33.

16. Z. Limpouchová; K. Procházka; Theoretical principles of fluorescence spectroscopy. In Fluorescence Studies of Polymer Containing Systems; Springer, Cham., 2016; pp. 91-149.

17. K. Kitamura; A.A. Omran; C. Nagata; Y. Kamijima; R. Tanaka; S. Takegami; T. Kitade; Chem. Pharm. Bull., 2006, 54, 972-976.

18. N. Seedher; Indian. J. Pharm. Sci., 2000, 62, 16-20.

19. J.J. Jing; B. Liu; X. Wang; X. Wang; L.L. He; X.Y. Guo; M.L. Xu; Q.Y. Li; B. Gao; B.Y. Dong; Lumin., 2017, 32, 1056-1065.

20. A.B. Khan; J.M. Khan; M.S. Ali; R.H. Khan; Spectrochim. Acta. A Mol. Biomol. Spectrosc., 2012, 97, 119-124.

21. X. An; J. Zhao; F. Cui; G. Qu; Arab. J. Chem., 2017, 10, 1781-1787.

22. J.R. Lakowicz; Principles of Fluorescence Spectroscopy; Plenum Press, New York, 1999; pp. 237-265.

23. J.R. Lakowicz; Quenching of Fluorescence. In: (eds) Principles of Fluorescence Spectroscopy; Springer, Boston, MA, 2006; pp. 277-330.

24. S.K. Dutta; S.K. Basu; K.K. Sen; Indian. J. Exp. Biol., 2006, 44, 123-127.

25. Z.J. Cheng; Y.T. Zhang; J. Mol. Struct., 2008, 889, 20-27. 
MIROSLAV SOVRLIĆ, RATOMIR JELIĆ, MARKO ANTONIJEVIĆ, ZORAN MARKOVIĆ, JOVICA TOMOVIĆ, EMINA MRKALIĆ

26. M. Shahlaei; B. Rahimi; M.R. Ashrafi-Kooshk; K. Sadrjavadi; R. Khodarahmi; J. of Luminiscence, 2015, 158, 91-98.

27. L. Brunton; J. Lazo; K. Parker; Goodman \& Gilman's The Pharmacological Basis of Therapeutics, 11th edn.; McGraw-Hill, New York, 2005.

28. N. Seedher; P. Agarwal; Drug. Metab. Pers. Ther., 2010, 25, 17-24.

29. Y.Q. Wang; H.M. Zhang; G.C. Zhang; W.H. Tao; S.H. Tang; J. Lumin., 2007, 126, 211-218.

30. M.G. Wen; X.B. Zhang; J.N. Tian; S.H. Ni; H.D. Bian; Y.L. Huang; H. Liang; J. Solute. Chem., 2009, 38, 391-401.

31. D. Leckband; Annu. Rev. Chem. Biomol. Eng., 2010, 1, 365-389.

32. R.A. Alberty; J. Phys. Chem. B., 2010, 114, 17003-17012.

33. J.Q. Lu; F. Jin; T.Q. Sun; X.W. Zhou; Int. J. Biol. Macromol., 2007, 40, 299-304.

34. D.B. Davies; L.N. Djimant; A.N. Veselkov; J. Chem. Soc. Faraday. Trans., 1996, 92, 383-390.

35. D.B. Davies; D.A. Veselkov; L.N. Djimant; A.N. Veselkov; Eur. Biophys. J., 2001, 30, 354-366.

36. P.D. Ross; S. Subramanian; Biochemistry., 1981, 20, 3096-3102.

37. J. Ghuman; P.A. Zunszain; I. Petitpas; A.A. Bhattacharya; M. Otagiri; S. Curry; J. Mol. Biol., 2005, 353, 38-52.

38. L. Trynda-Lemiesz; Bioorg. Med. Chem., 2004, 12, 3269-3275.

39. P.A. Ravindranath; S. Forli; D.S. Goodsell; A.J. Olson; M.F. Sanner; PLoS. Comput. Biol. 2015, 11, e1004586.

40. A.D. Becke; Phys. Rev. A.,1988, 38, 3098-3100.

41. A.D., Becke; J. Chem. Phys., 1993, 98, 5648.

42. [dataset] M.J. Frisch; G.W. Trucks; H.B. Schlegel; G.E. Scuseria; M.A. Robb; J.R. Cheeseman; G. Scalmani; V. Barone; B. Mennucci; G.A. Petersson; H. Nakatsuji; M. Caricato; X. Li; H.P. Hratchian; A.F. Izmaylov; J. Bloino; G. Zheng; J.L. Sonnenberg; M. Hada; M. Ehara; K. Toyota; R. Fukuda; J. Hasegawa; M. Ishida; T. Nakajima; Y. Honda; O. Kitao; H. Nakai; T. Vreven; J. Montgomery; J. A. Peralta; F. Ogliaro; M. Bearpark; J.J. Heyd; E. Brothers; K.N. Kudin; V.N. Staroverov; R. Kobayashi; J. Normand; K. Raghavachari; A. Rendell; J.C. Burant; S.S. Iyengar; J. Tomasi; M. Cossi; N. Rega; J.M. Millam; M. Klene; J.E. Knox; J.B. Cross; V. Bakken; C. Adamo; J. Jaramillo; R. Gomperts; R.E. Stratmann; O. Yazyev; A.J. Austin; R. Cammi; C. Pomelli; J.W. Ochterski; R.L. Martin; K. Morokuma; V.G. Zakrzewski; G.A. Voth; P. Salvador; J.J. Dannenberg; S. Dapprich; A.D. Daniels; Ö. Farkas; J.B. Foresman; J. V. Ortiz; J. Cioslowski; D.J. Fox; Gaussian 09. Revision D. Gaussian Inc, Wallingford, 2009.

43. I. Petitpas; C.E. Petersen; C.E. Ha; A.A. Bhattacharya; P.A. Zunszain; J. Ghuman; N.V. Bhagavan; S. Curry; Proc. Natl. Acad. Sci., 2005, 100, 6440-6445.

44. D.S. BIOVIA; Discovery studio visualizer, Release. San Diego: Dassault Systèmes, 2017.

45. G.M. Morris; R. Huey; W. Lindstrom; M.F. Sanner; R.K. Belew; D.S. Goodsell; A.J. Olson; J. Comput. Chem., 2009, 30, 2785-2791. 